\title{
PERBANDINGAN PEMERIKSAAN TINJA METODE SEDIMENTASI DENGAN METODE NATIF DALAM MENDETEKSI SOIL TRANSMITTED HELMINTH
}

\author{
Nurhidayanti ${ }^{1}$, Obie Permana ${ }^{2}$ \\ ${ }^{1}$ Program Study DIV Teknologi Laboratorium Medis IKesT Muhammadiyah Palembang \\ Email: nuri89_yanti@yahoo.com \\ ${ }^{2}$ Program Study DIV Teknologi Laboratorium Medis IKesT Muhammadiyah Palembang \\ Email: obiepermana14@gmail.com
}

\begin{abstract}
ABSTRAK
Soil Transmitted Helminth (STH) adalah infeksi parasit usus yang paling sering terjadi dan merupakan salah satu penyumbang beban penyakit global. Diagnosis penyakit Soil Transmitted Helminth dapat dilakukan menggunakan metode sedimentasi dan metode natif. Penelitian ini bertujuan untuk mengetahui perbedaan metode sedimentasi dan metode natif dalam mendeteksi Soil Transmitted Helminth Jenis penelitian yang dilakukan dalam bentuk true eksperimental. Penelitian ini dilakukan pada tanggal 27-29 Maret 2021 di Laboratorium Mikrobilogi Institut Ilmu Kesehatan dan Teknologi Muhammadiyah Palembang yang berjumlah 35 responden. Hasil yang didapat pada penelitian ini adalah sebanyak 2 sampel positif dan 33 sampel negatif. Pada sampel 1 terdapat 2 jenis telur Soil Transmitted Helminth yaitu telur Ascaris lumbricoides dan Trichuris trichiura pada metode sedimentasi dan metode natif, sedangkan pada sampel 5 terdapat telur Ascaris lumbricoides saja pada metode natif. Hasil data penelitian dilakukan menggunakan uji alternatif Wilcoxon dengan nilai $P=0,317$ artinya tidak ada perbedaan yang signifikan. Adapun kesimpulan penelitian ini didapatkan hasil pemeriksaan bahwa tidak terdapat perbedaan pada metode sedimentasi dengan metode natif.
\end{abstract}

Kata Kunci: STH, Metode Sedimetasi, Metode Natif

\section{ABSTRACT}

Soil Transmitted Helminth (STH) is the most common intestinal parasific infection and in one of the contributors to the global disease burden. Diagnosis of Soil Transmitted Helminth desease can be done using sedimentation method and natif method. This study aims to find out the differences in sedimentation methods and natif methods in deteting Soil Transmitted Helminth Type of research conducted ind true experimental form. This research was conducted on March 27-29, 2021 at the Microbiology Laboratory of Muhammadiyah Institute of Health and Technology Palembang which numbered 35 respondents. The results obtained in this study were as many as 2 positive samples and 33 negative samples. In sample 1 there are 2 types of eggs Soil Transmitted Helminth namely eggs Ascaris lumbricoides and Trichuris trichiura on sedimentation method and natif method, while in sample 5 there are eggs Ascaris lumbricoides only on the natif method. The results of the research data were conduted using an alternative test Wilcoxon with a value of $P=0.317$ means there is no difference that signifikan.the conclusion of this study was obtained by the examination that there is no difference in sedimentation with natiif method.

Keywords: STH, Sedimentasi Method, Natif Method

Universitas Sari Mutiara Indonesia

DOI: https://doi.org/10.51544/jalm.v6i2.2000 


\section{PENDAHULUAN}

Cacing merupakan masalah utama kesehatan anak-anak Indonesia cacing yang biasanya menginfeksi anak merupakan cacing yang habitatnya disaluran pencernaan manusia dan hewan. Jenis cacing yang biasanya menginfeksi merupakan cacing nematode usus jenis cacing nematode golongan Soil Transmitted Helminth yaitu: cacing gelang (Ascaris lumbricoides), cacing tambang (ancylostoma duodenale dan neacator americanus), cacing cambuk (Trichuris tricihura), cacing benang (Strongyloides stercoralis)(Yunita \& Ardiansyah, 2018)

Penularan cacing Soil Transmitted Helminths disebabkan oleh beberapa faktor termasuk dalam kebersihan yang masih rendah contohnya makan tanpa menggunakan sendok dan tidak mencuci tangan terlebih dahulu, kuku jemari tangan yang tidak secara rutin dipotong dan sanitasi yang buruk. Jika larva cacing tertelan pada saat melakukan aktivitas maka siklus hidup cacing yang menginfeksi akan dimulai dan sempurna sehingga terjadi infeksi pada manusia. Mahkluk hidup yang ada didalam tanah berupa cacing dan bakteribakteri yang merugikan. Sebagian besar masyarakat masih membuang hajat ditanah, sungai, parit dan pematang sawah. Bahkan sering juga di perkarangan rumah sendiri. (Yunita \& Ardiansyah, 2018)

Penggunaan metode pemeriksaan tinja yang memiliki tingkat sensitifitas tinggi sangat penting guna mendapat status kecacingan yang akurat. Status kecacingan seseorang dapat dipastikan dengan menentukan telur cacing pada pemeriksaan laboratorium tinja Pemeriksaan mikroskopis terdiri dari dua pemeriksaan yaitu pemeriksaan kualitatif dan kuantitatif. Pemeriksaan kualitatif dapat dilakukan dengan berbagai cara seperti pemeriksaan langsung (direct slide) yang merupakan pemeriksaan rutin ulang dilakukan, metode flotasi, metode slotip, teknik sedian tebal dan metode sedimentasi. Pemeriksaan kualitatif dengan beberapa metode yaitu metode Stroll, Flotasi kualitatif dan metode Kato Katz. (Permatasari et al., 2020)

Menurut penelitian Regina (2018) mengatakan Metode natif merupakan gold standar pemeriksaan kualitatif tinja karena sensitif, murah, mudah dan cepat. Namun kurang sensitif pada infeksi ringan. Metode natif sederhana ini dilakukan dengan sedikit suspensi fases menggunakan ujung gelas obyek. Preparat ditutup dengan cover glass untuk dapat diperiksa dengan mikroskop dengan pembesaran 10x-40x. (Regina et al., 2018)

Metode sedimentasi adalah metode menggunakan larutan dengan berat jenis yang lebih rendah dari organisme parasit dan memanfaatkan gaya sentrifugal, senhingga parasit dapat mengendap dibawah. Metode sedimentasi yang sering digunakan berdasarkan reagensia adalah metode sedimentasi dengan $\mathrm{NaOH} 0,2 \%$ dan metode sedimentasi dengan $\mathrm{NaCl}$ 0,9\%. (Permatasari et al., 2020)

Tujuan penelitian ini adalah untuk mengetahui hasil perbandingan pemeriksaan tinja Metode Sedimentasi dengan Metode Natif dalam mendeteksi Soil Transmitted Helminth. Adapun manfaat dari penelitian ini yaitu penelitian ini dilakukan untuk menambah wawasan, ilmu pengetahuan, dan keterampilan peneliti tentang perbandingan pemeriksaan tinja antara Metode Sedimentasi dan Metode Natif dalam mendeteksi Soil Transmitted Helminth.

\section{METODE PENELITIAN}

Jenis penelitian yang digunakan yaitu True Eksprerimental. Penelitian ini dilakukan pada tanggal 27-29 Maret 2021 bertempat di Laboratorium Mikrobiologi Institut Ilmu Kesehatan dan Teknologi Muhammadiyah Palembang. Populasi penelitian ini adalah siswa/siswi SD Negeri 221 Kertapati Palembang kelas 2 dan kelas 3 yang berjumlah 44. Kemudian sampel dilakukan dengan menggunakan Teknik Random Sampling untuk 
menentukan besaran sampel dilakukan perhitungan menggunakan rumus Rumus Isaach dan Michael dengan tingkat kesalahan $10 \%$ maka didapatkan jumlah sampel yang akan diteleti sebanyak 35 responden. Dengan kriteria inklusi dan ekslusi sebagai berikut:

Kriteria inklusi

1. Usia 7-8 tahun
2. Bersedia menjadi responden

3. Kualitas sampel baik

Kriteria ekslusi

1. Tidak bersedia menjadi responden

2. Data yang tidak lengkap

Berdasarkan variabel dependen dan variabel independen dalam penelitian ini maka disusun pada tabel 1 .

Table 1. Definisi Operasional

\begin{tabular}{|c|c|c|c|c|}
\hline No & Variabel & Definisi Operasional & Hasil Ukur & Skala Ukur \\
\hline 1 & $\begin{array}{l}\text { Variabel } \\
\text { Dependen: } \\
\text { Metode } \\
\text { Sedimentasi }\end{array}$ & $\begin{array}{l}\text { Adalah metode menggunakan } \\
\text { larutan dengan berat jenis yang } \\
\text { lebih rendah dari organisme } \\
\text { parasite dan memanfaatkan } \\
\text { gaya sentrifugal, sehinga } \\
\text { parasite dapat mengendap } \\
\text { dibawah. metode sedimentasi } \\
\text { dengan } \mathrm{NaCl} 0,9 \%\end{array}$ & $\begin{array}{l}\text { Positif : } \\
\text { Ditemukan telur } \\
\text { SoilTransmitted } \\
\text { Helminth } \\
\\
\text { Negatif : } \\
\text { Tidakditemukantel } \\
\text { ur SoilTransmitted } \\
\text { Helminth }\end{array}$ & Nominal \\
\hline 2 & $\begin{array}{l}\text { Variabel } \\
\text { Dependen: } \\
\text { Metode Natif }\end{array}$ & $\begin{array}{l}\text { Merupakan gold standard } \\
\text { pemeriksaan kualitatif tinja } \\
\text { karena sensitive, murah, mudah } \\
\text { dan pengerjaan cepat. Cara } \\
\text { pemeriksaan ini menggunakan } \\
\text { laruran Eosin 2\% }\end{array}$ & $\begin{array}{l}\text { Positif : } \\
\text { Ditemukantelur } \\
\text { SoilTransmitted } \\
\text { Helminth } \\
\\
\text { Negatif : } \\
\text { Tidakditemukan } \\
\text { telur Soil } \\
\text { Transmitted } \\
\text { Helminth }\end{array}$ & Nominal \\
\hline 3 & $\begin{array}{l}\text { Variabel } \\
\text { Independen : } \\
\text { Hasil } \\
\text { pemeriksaan } \\
\text { telur STH }\end{array}$ & 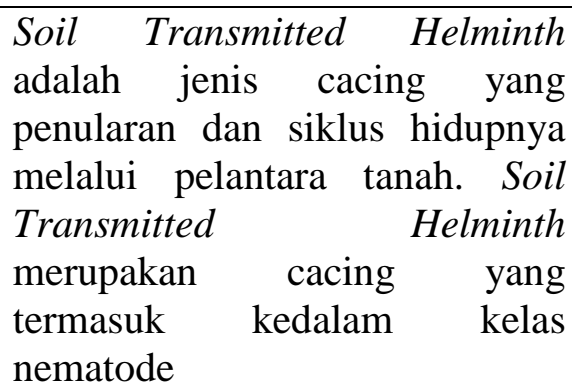 & Hasil pemeriksaan & Rasio \\
\hline
\end{tabular}

Adapun proses pemeriksaan metode sedimentasi dan metode natif sebagai berikut:

Pada pemeriksaan menggunakan metode sedimentasi pertama menyiapkan alat dan bahan yang akan digunakan, kemudian ambil 3-4 tetes konsentrat tinja, masukkan ke dalam tabung reaksi dan tambahkan $\mathrm{NaCl}$ 0,9\%hingga 3/4 tabung, kemudian di tutup dengan kapas. Sentrifuge dengan kecepatan $2000 \mathrm{rpm}$ selama 10 menit dan terbentuk 2 lapisan yakni lapisan jernih dan endapan, dibuang bagian yang jernih dengan jalan menuangkan tabung reaksi secara 
cepat dan endapan di periksa lalu ambil endapan 1 tetes letakkan di atas objek glass, tutup dengan kaca penutup diperiksa dibawah mikroskop dengan perbesaran 10xdan 40x. (Sihite, 2019)

Cara kerja Pemeriksaan feses metode natif secara langsung dengan larutan Eosin 2\% adalah 1 tetes larutan Eosin 2\% diteteskan di atas kaca objek. Kemudian feses diambil dengan lidi $( \pm 2 \mathrm{mg})$ dan dicampurkan dengan 1-2 tetes larutan Eosin 2\% sampai homogen. Apabila terdapat bagian-bagian kasar dibuang. Selanjutnya, ditutup dengan kaca penutup ukuran 20 × $20 \mathrm{~mm}$ sampai kaca penutup rata menutupi sediaan sehingga tidak terbentuk gelembung-gelembung udara. Setelah itu,sediaan diamati dengan menggunakan pembesaran rendah (objektif 10x) dan objektif 40x. (Aulia Maulida, 2016)

Data yang diperoleh merupakan data primer dan berskala rasio sehingga dilakukan analisa data kualitatif menggunakan uji statistik paramentrik Uji $\mathrm{T}$ berpasangan dan apabila data Uji normalitas tidak terdistribusi maka dilakukan dengan Uji alternatif Wilcoxon dengan menggunakan program SPSS versi 16.0 dengan derajat kesalahan $10 \%$.

\section{HASIL DAN PEMBAHASAN}

Berdasarkan hasil penelitian pemeriksaan tinja yang telah dilakukan didapatkan hasil data berupa karakteristik responden yaitu jenis kelamin, usia responden dan data hasil penelitian sebagai berikut:

1. Karakteristik Responden

Berdasarkan penelitian yang telah dilakukan pada Siswa/Siswi Sekolah Dasar SDN 221 Kertapati Palembang dengan total sampel sebanyak 35 siswa. Hal tersebut terlihat pada tabel dibawah ini:

a. Jenis Kelamin

Tabel 2. Distribusi Frekuensi Responden Berdasarkan Jenis Kelamin Siswa SDN 221 Kertapati Palembang Kelas 2 dan Kelas 3 Tahun 2021.

\begin{tabular}{ccc}
\hline Jenis Kelamin & Frekuensi & Presentasi (\%) \\
\hline Perempuan & 20 & 57,1 \\
Laki-laki & 15 & 42,9 \\
\hline Jumlah & 35 & 100 \\
\hline
\end{tabular}

Berdasarkan tabel 2. diatas dapat dilihat bahwa dari 35 responden, sebagian besar responden memiliki jenis kelamin perempuan yaitu 20 responden $(57,1 \%)$ dan sebagian kecil adalah responden yang memiliki jenis kelamin lakilaki yaitu sebanyak 15 responden $(42,9 \%)$.

b. Usia

Tabel 3.Distribusi Frekuensi Responden Berdasarkan Usia Pada Siswa SDN 221 Kertapati Palembang Kelas 2 dan Kelas 3 tahun 2021.

\begin{tabular}{ccc}
\hline Usia & Frekuensi & Presentasi $(\%)$ \\
\hline 7 & 17 & 48,6 \\
8 & 18 & 51,4 \\
\hline Total & 35 & 100 \\
\hline
\end{tabular}

Berdasarkan tabel 4.2 diatas dapat dilihat bahwa dari 35 responden, sebagian besar responden berusia 8 tahun yaitu sebanyak
18 responden $(51,4 \%)$ dan sebagian kecil responden berusia 7 tahun yaitu 17 responden $(48,6 \%)$. 
2. Data Hasil penelitian

Tabel 4. Data Hasil Pemeriksaan Telur Cacing STH

\begin{tabular}{llllclllll}
\hline \multicolumn{9}{c}{ Metode Sedimentasi } & \multicolumn{5}{c}{ Metode Natif } \\
\hline No & Kode & Al & Tt & Hookwor & Ss & Al & Tt & Hookworm & Ss \\
& Sampel & & & $\boldsymbol{m}$ & & & & & \\
\hline 1 & S1 & + & + & - & - & + & + & - & - \\
2 & S2 & - & - & - & - & - & - & - & - \\
3 & S3 & - & - & - & - & - & - & - & - \\
4 & S4 & - & - & - & - & - & - & - & - \\
5 & S5 & + & - & - & - & + & - & - & - \\
6 & S6 & - & - & - & - & - & - & - & - \\
7 & S7 & - & - & - & - & - & - & - & - \\
8 & S8 & - & - & - & - & - & - & - & - \\
9 & S9 & - & - & - & - & - & - & - & - \\
10 & S10 & - & - & - & - & - & - & - & - \\
11 & S11 & - & - & - & - & - & - & - & - \\
12 & S12 & - & - & - & - & - & - & - & - \\
13 & S13 & - & - & - & - & - & - & - & - \\
14 & S14 & - & - & - & - & - & - & - & - \\
15 & S15 & - & - & - & - & - & - & - & - \\
16 & S16 & - & - & - & - & - & - & - & - \\
17 & S17 & - & - & - & - & - & - & - & - \\
18 & S18 & - & - & - & - & - & - & - & - \\
19 & S19 & - & - & - & - & - & - & - & - \\
20 & S20 & - & - & - & - & - & - & - & - \\
21 & S21 & - & - & - & - & - & - & - & - \\
22 & S22 & - & - & - & - & - & - & - & - \\
23 & S23 & - & - & - & - & - & - & - & - \\
24 & S24 & - & - & - & - & - & - & - & - \\
25 & S25 & - & - & - & - & - & - & - & - \\
26 & S26 & - & - & - & - & - & - & - & - \\
27 & S27 & - & - & - & - & - & - & - & - \\
28 & S28 & - & - & - & - & - & - & - & - \\
29 & S29 & - & - & - & - & - & - & - & - \\
30 & S30 & - & - & - & - & - & - & - & - \\
31 & S31 & - & - & - & - & - & - & - & - \\
32 & S32 & - & - & - & - & - & - & - & - \\
33 & S33 & - & - & - & - & - & - & - & - \\
34 & S34 & - & - & - & - & - & - & - & - \\
35 & S35 & - & - & - & - & - & - & - & - \\
\hline & & & & & & & & &
\end{tabular}

Berdasarkan tabel 3. dari 35 sampel yang diperiksa terdapat 2 sampel yang positif dan 33 negatif. Pada pemeriksaan menggunakan metode sedimentasi hasil yang diperoleh dari 35 sampel yang di periksa terdapat 2 sampel yang positif telur STH yaitu pada sampel dengan kode S1 (sampel 1) dan S5 (sampel 5). Pada sampel 1 terdapat 2 jenis telur Soil Transmitted Helminth yaitu telur Ascaris lumbricoides danTrichuris trichiura 
sedangkan pada sampel 5 hanya terdapat telur Ascaris lumbricoides saja. Pada pemeriksaan menggunakan metode natif hasil yang diperoleh dari 35 sampel yang diperiksa terdapat 2 sampel yang positif telur Soil Transmitted Helminth yaitu pada sampel dengan kode S1 (sampel 1) dan S5 (sampel 5). Pada sampel 1 terdapat 2 jenis telur Soil Transmitted Helminth yaitu telur Ascaris lumbricoides dan Trichuris trichiura sedangkan pada sampel 5 hanya terdapat telur Ascaris lumbricoides saja.

3. Hasil Gambar Telur Soil Transmitted Helminths Metode Sedimentasi

Pada pemeriksaan yang telah dilakukan menggunakan metode sedimentasi terdapat 2 sampel yang positif telur Soil Transmitted Helminth yaitu pada sampe 1 dengan kode S1 (sampel 1) dan S5 (sampel 5). Pada sampel 1 terdapat 2 jenis telur Soil Transmitted Helminth yang ditemukan yaitu telur Ascaris lumbricoides dantelur Trichuris trichiura. Pemeriksaan dilakukan dengan menggunakan mikroskop dengan perbesaran 10x dan 40x pada sampel 1 dan sampel 5 sebagai berikut:

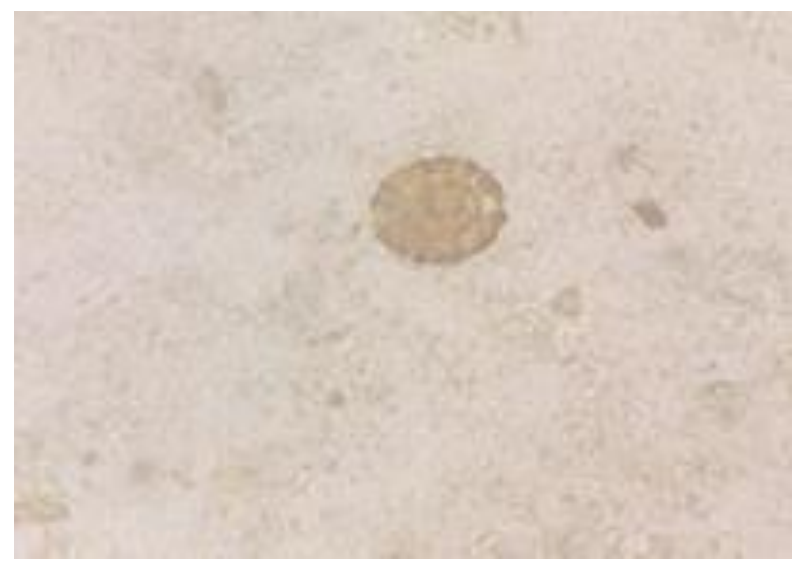

\section{Gambar 1. Telur Ascaris lumbricoides Metode Sedimentasi}

Pada gambar 1. Terlihat Telur Ascaris lumbricoides fertil: bentuk oval, warna kuning kecoklatan, berisi embrio, lapisan telur tebal dan berkelok, lapisan dalamnya relatif halus dan lapang padang di mikroskop lebih jelas

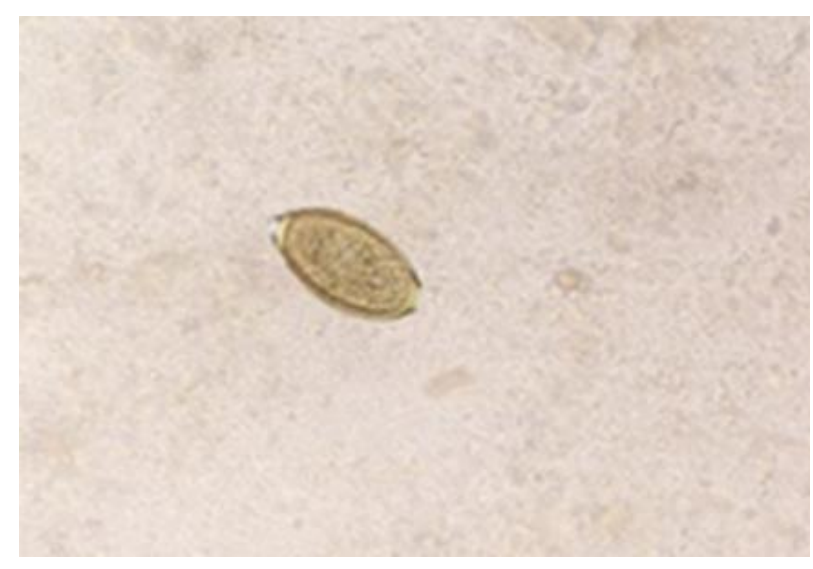

\section{Gambar 2. Telur Trichuris trichiura Metode sedimentasi}

Pada gambar 2. Terlihat telur Trichuris trichiura berbentuk seperti guci atau tempayan, kulit luar berwarna kuning, kulit dalam bewarna transparan dan kedua kutubnya terdapat operculum, yaitu semacam penutup yang jernih menonjol yang dindingnya terdiri atas dua lapis yaitu mukoid plug dan lapang pandang di mikroskop terlihat lebih jelas.

\section{Hasil Gambar Telur Soil Transmitted Helminths Metode Natif}

Pada pemeriksaan yang telah dilakukan menggunakan metode natif terdapat 2 sampel yang positif telur Soil Transmitted Helminth yaitu pada sampe 1 dengan kode S1 (sampel 1) dan S5 (sampel 5). Pada sampel 1 terdapat 2 jenis telur Soil Transmitted Helminth yang ditemukan yaitu telur Ascaris lumbricoides dan telur Trichuris trichiura. Pemeriksaan dilakukan dengan menggunakan mikroskop dengan perbesaran 10x dan 40x pada sampel 1 dan sampel 5 sebagai berikut: 


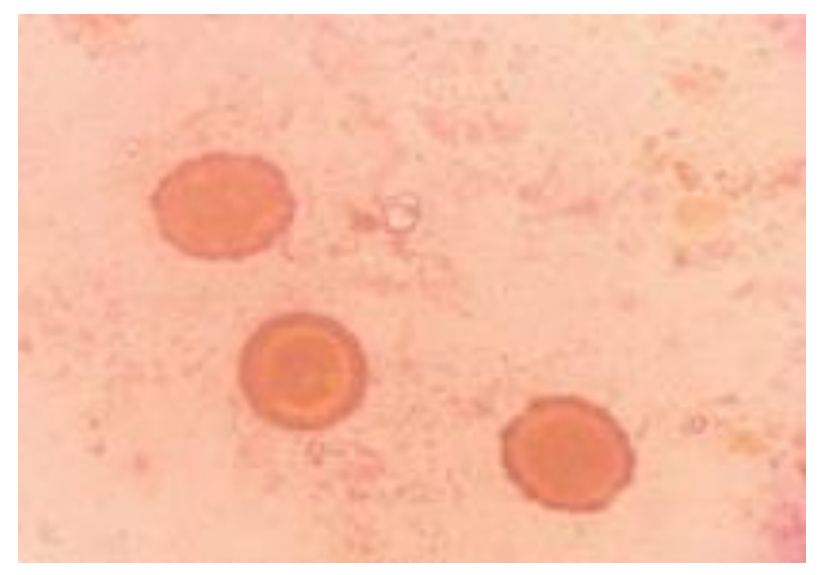

\section{Gambar 3. Telur Ascari lumbricoides Metode Natif}

Pada gambar 3. Terlihat Telur Ascaris lumbricoides fertil: bentuk oval, warna kuning kecoklatan, berisi embrio, lapisan telur tebal dan berkelok, lapisan dalamnya relatif halus dan lapang padang di mikroskop kurang jelas karena warna lapang pandang dimikroskop berwarna merah.

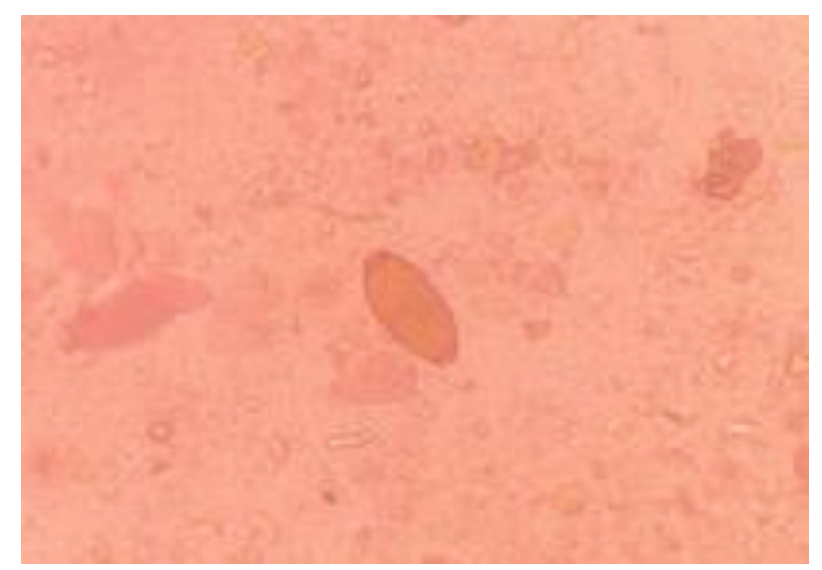

\section{Gambar 4. Telur Trichuris trichiura Metode Sedimentasi}

Pada gambar 4. Terlihat telur Trichuris trichiura berbentuk seperti guci atau tempayan, kulit luar berwarna kuning, kulit dalam bewarna transparan dan kedua kutubnya terdapat operculum, yaitu semacam penutup yang jernih menonjol yang dindingnya terdiri atas dua lapis yaitu mukoid plug dan lapang padang di mikroskop kurang jelas karena warna lapang pandang dimikroskop berwarna merah.

Dari pemeriksaan 4 jenis telur Soil Transmitted Helminth yaitu cacing gelang (Ascaris limbricoides), cacing cambuk (Trichuris trichiura), cacing tambang (Necator Americanus dan Ancylosoma duodenale), dan cacing benang (Strongyloides stercoralis) spesies yang ditemukan hanya telur acaris lumbricoides dan Trichuris trichiura hal ini sejalan dengan penelitian Regina (2018) Yang menjelaskan prevalensi telur Soil Transmitted Helminth di banyak Negara termasuk di Indonesia yang menunjukkan bahwa memang prevalensi spesies ini tertinggi. Faktor tanah, iklim dan suhu di Indonesia yang berpengaruh pada tingginya prevalensi tersebut. Jenis cacing ini memerlukan tanah pasir yang gembur dan terlindung dari sinar matahaari langsung. Suhu optimum yang dibutuhkan kurang lebih 23o$32^{\circ} \mathrm{C}$.

Menurut penelitian Bedah (2018) telur Ascaris lumbricoides mempunyai ciri-ciri bentuk bulat oval, ukuran 60x45 mikron, warna kecoklatan, dinding telur yang kuat terdiri dari bagian luar (dibentuk dari lapisan selaput albumin sengan permukaan berupa tonjolan-tonjolan atau bergerigi yang berwarna kecoklatan karena pigmen empedu) dan bagian dalam dinding telur terdiri dari lapisan vitelin yang liat, sehinga telur dapat tetap taahan lama sampai 1 tahun. (Bedah \& Syafitri, 2019)

Menurut penelitian Sumanto (2016) mengatakan bahwa telur cacing cambuk (Trichuris trichiura) berukuran 50 x 25 mikron, bentuknya khas seperti tempayan kayu atau biji melon. Pada kedua kutub telur memiliki tonjolan yang jernih yang dinakaman mucoid plug. Tonjolan pada kedua kutub kulit telur tersebut bagian luar berwarna kekuningan dan bagian dalamnya jernih. Pada stadium lanjut telur kadang tampak sudah berisi larva cacing. (Sumanto, 2016)

Pada pemeriksaan menggunakan metode 
sedimentasi dan metode natif terdapat perbedaan pada lapang pandang di mikroskop. Pada metode sedimentatsi bentuk dan warna telur Ascaris lumbricoides dan Trichuris trichiura lebih jelas dan mudah dilihat sedangkan pada metode natif bentuk dan warna telur Ascaris lumbricoides dan Trichuris trichiura terlihat kurang jelas yaitu warna latar belakang berwarna merah dan tidak terdapat perbedaan latar belakang dengan warna telur. Warna morulla merah dan dinding merah tua hampir menyerupai kotoran dari fases.

Menurut penelitian Sihite (2019. mengatakan bahwa reagensia $\mathrm{NaCl} 0,9 \%$ tidak meliliki pelepasan panas bila dilarutkan dalam air dan tidak memiliki sifat korosif, hal ini dapat dilihat pada sedian feses dimana sisa makanan masih mempertahankan beberapa bentuk aslinya, karenanya hasil yang menggunakan reagensia $\mathrm{NaCl} 0,9 \%$ lebih jernih dan bersih. Selain itu reagensia $\mathrm{NaCl}$ $0,9 \%$ dapat digunakan pada metode sedimentsi.

(Pratama et al., 2020)
Menurut penelitian Maulida (2016) mengatakan reagensia eosin $0,2 \%$ pada lapang pandang mepunyai latar belakang berwarna merah dan bentuk telur kurang jelas dan tidak terdapat perbedan latar belakang dengan warna telur hampir menyerupai kotoran dari feses. Selain itu, pengamatan sediaan dengan pewarnaan eosin harus dengan dilakukan pengamatan yang lebih teliti untuk memperoreh telur Ascaris lumbricoides dan telur Trichuris trichiura. (Aulia Maulida, 2016)

Setelah didapatkan hasil penelitian diatas maka data diolah mengunakan aplikasi SPSSversi 16.0 untuk mencari nilai normal atau tidak normal pada pemeriksaan tersebut, sehingga data bisa ditentukan apakah terdapat perbedaan pada kedua metode ini yaitu metode sedimentasi dan metode natif dalam mendeteksi telurSoil Transmitted Helminths. Hasil analisis data didapatkan sebagai berikut:

Tabel 5. Hasil Uji Wilcoxon

\begin{tabular}{lcccc}
\hline \multicolumn{1}{c}{ Metode } & $\mathbf{N}$ & Sig & $\begin{array}{c}\text { Batas } \\
\text { Keberterimaan }\end{array}$ & Keterangan \\
\hline Sedimentasi & 35 & 0,317 & $P \geq 0,05$ & $\begin{array}{c}\text { Data tidak } \\
\text { terdapat } \\
\text { perbedaan }\end{array}$ \\
Natif & & & & \\
\hline
\end{tabular}

Berdasarkan Hasil table 4. diatas menggunakan uji alternatif Wilcoxon didapatkan nilai $p \geq 0,317$ yang lebih besar dari $0,05(\geq 0,05)$, maka dapat diambil kesimpulan bahwa tidak ada perbedaan yang signifikan antara perbandingan metode sedimentasi dan metode natif dalam mendeteksi telur Soil Transmitted Helminth.

Dari hasil penelitian yang telah dilakukan peneliti mengenai Perbandingan Pemeriksaan Tinja Metode Sedimentasi Dengan Metode Natif Dalam Mendeteksi Soil Transmitted Helminth yang menunjukkan bahwa tidak terdapat perbedaan yang siqnifikan antara perbandingan pemeriksaan metode sedimentasi dengan metode natif dengan nilai $p$ value $0,317(p>0,05)$.

Hasil penelitian ini sejalan dengan penelitian yang dilakukan oleh Regina (2018) mengenai Perbandingan Pemeriksaan Tinja Antara Metode Sedimentasi Biasa Dan Metode Sedimentasi Formol-Ether dalam Mendeteksi Soil-Transmitted Helminth yang menunjukkan bahwa tidak ada perbedaan yang signifikan antara Perbandingan Pemeriksaan Tinja Antara Metode Sedimentasi Biasa Dan Metode Sedimentasi Formol-Ether denagan nilai $P$ 
Positif terinfeksi telur Soil-Transmitted Helminth sebanyak 24 sampel dan sebanyak 5 sampel memiliki 2 jenis telur cacing yang berbeda yaitu Ascaris lumbricoides dan cacing tambang. (Permatasari et al., 2020)

Hasil penelitian ini sejalan dengan penelitian yang telah dilakukan Pratama (2015) mengenai Perbandingan Metode Mini FLOTAC dengan Metode Kato-Katz Pada Anak Yang Terinfeksi Cacing Usus SoilTransmitted Helminth yang menunjukkan tidak ada perbedaan yang siqnifikan antara perbandingan Metode FLOTAC dengan Metode Kato-Katz dengan nilai $P$ value 0,773 $(p>0,05)$. (Sjafii, 2017)

Hasil penelitian ini juga sejalan dengan penelitian yang telah dilakukan Sjafii (2017) mengenai Perbandingan Efektififitas Metode School-Based Deworming Dengan Metode Community-Based Deworming Pada Anak Sekolah Dasar Dengan Infeksi SoilTransmitted Helminth yang menunjukkan tidak ada perbedaan yang signifikan antara perbandingan metode Metode School-Based Deworming Dengan Metode Community-Based Deworming karena nilai $p>0,05$.

\section{SIMPULAN}

Berdasarkan hasil penelitian yang telah dilakukan tentang perbandingan pemeriksaan tinja metode sedimentasi dengan metode natif dalam mendeteksi Soil Transmitted Helminth dapat diambil kesimpulan sebagai berikut:

1. Didapatkan hasil pemeriksaan pada metode sedimentasi di temukan telur pada sampel fases dengan kode sampel S1 dan sampel S5. Pada sampel 1 ditemukan dua jenis telur Soil Transmitted Helminth yaitu telur Ascaris lumbricoides dan Trichuris trichiura sedangkan pada sampel 5 hanya ditemukan telur Ascaris lumbricoides saja.

2. Didapatkan hasil pemeriksaan pada metode natif di temukan telur pada sampel fases dengan kode sampel S1 dan S5. Pada sampel S1 dan S5 ditemukan telur Ascaris lumbricoides saja.
3. Didapatkan hasil pemeriksaan pada metode sedimentasi dan metode natif tidak terdapat perbandigan pada kedua metode hanya saja pada metode sedimentasi lapang pandang di mikroskop lebih jelas dibandingkan dengan metode natif.

\section{UCAPAN TERIMAKASIH}

Dalam penulisan skripsi ini, penulis tidak terlepas dari bantuan, dorongan serta dukungan dari berbagai pihak. Untukitu pada kesempatan ini penulis ingin menyampaikan terimakasih yang sebesar-besarnya kepada dosen pembimbing dan dosen penguji yang telah memberi bimbingan dan masukkan dan petugas laboratorium IkesT MP yang telah membatu dalam proses penelitian di laboratori

\section{DAFTAR PUSTAKA}

Aulia Maulida. (2016). Perbedaan Kualitas Sediaan Telur Cacing Gelang (Ascaris Lumbricoides, Linnaeus 1758) Menggunakan Pewarnaan Eosin dan Pewarnaan Giemsa. Muhammadiya Semarang.

Bedah, S., \& Syafitri, A. (2019). Infeksi Kecacingan Pada Anak Usia 8-14 Tahun Di Rw 007 Tanjung Lengkong Kelurahan Bidaracina, Jatinegara, Jakarta Timur. Jurnal Ilmiah Kesehatan, 10(1), 20-31. https://doi.org/10.37012/jik.v10i1.13

Permatasari, D. A., Kusriningrum, R., Tjuk, I. R., Sri, M. S., Endang, S., \& Mustofa, H. E. (2020). Prevalence and Worm Infection Degree Gastroinstestional on Duck ( Anas javanica ) in Two Different Geographical Territory. 4(1).

Pratama, R. P., Sari, M. P., \& Majawati, E. S. (2020). Artikel Penelitian Infeksi Cacing Usus pada Anak Sekolah Dasar Negeri Cilincing 06 Jakarta Intestinal Helminth Infection in Children of Cilincing State Elementary School 06. Jurnal Kedokteran Meditek, 26(3), 132-138. 
Regina, M. P., Halleyantoro, R., \& Bakri, S. (2018). Perbandingan Pemeriksaan Tinja Antara Metode Sedimentasi Biasa Dan Metode Sedimentasi Formol-Ether Dalam Mendeteksi Soil-Transmitted Helminth. Diponegoro Medical Journal (Jurnal Kedokteran Diponegoro), 7(2), 527-537.

Sihite, A. (2019). Perbandingan Jumlah dan Keragaman Telur Cacing Soil Transmitted Helminth (STH) Menggunakan Metode Sedimentasi Reagensia $\mathrm{NaOH} 0,2 \%$ dan $\mathrm{NaCL} \quad 0,9 \%$. Politehnik Kesehatan Kemenken RI Medan Jurusan Analis Kesehatan.

Sjafii, R. (2017). Perbandingan Efektifitas Metode School Based Deworming dan Community Based Deworming Pada Anak Sekolah Dasar dengan infeksi Soild Transmitted Helminth. Fakultas Kedokteran Universita Sumatera Utara Medan.
Sumanto, D. (2016). Parasitologi Kesehatan Masyarakat (H. Wartomo (ed.)). Yoga Pratama Semarang.

Yunita, \& Ardiansyah. (2018). Identifikiasi Telur Soil Transmitted Helmint Pada Feces Anak SD INPRES 094151 Parapat Kabupaten Simalungun. 4(2), 2-5. 